\title{
Guidelines for resuscitation and transfer of patients with serious head injury
}

\author{
Douglas Gentleman, Mark Dearden, Susan Midgley, Donald Maclean
}

Dundee Royal Infirmary, Dundee DD1 9ND

Douglas Gentleman, consultant neurosurgeon

Western General Hospital, Edinburgh

Mark Dearden, consultant neuroanaesthetist

Susan Midgley, research registrar in neurosciences

Law Hospital, Carluke, Lanarkshire

Donald Maclean, consultant anaesthetist

Correspondence to: Mr Gentleman.

$B M \mp 1993 ; 307: 547-52$

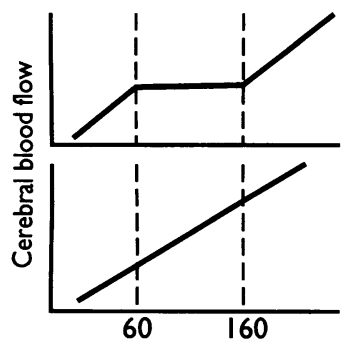

FIG 2-Cerebral

Cerebral perfusion pressure $(\mathrm{mm} \mathrm{Hg})$

autoregulation-(top) normal: constant cerebral blood flow within wide limits of cerebral perfusion pressure; (bottom) impaired autoregulation after serious head injury: "pressure passive" cerebral blood flow
Secondary brain damage after head injury causes much avoidable death and disability, and has major resource implications. ${ }^{14}$ There are two main causes: delayed diagnosis and treatment of intracranial haematomas and failure to correct systemic hypoxaemia and hypotension. Although it is perhaps not the ideal approach to treatment, many head injured patients are admitted to hospitals that do not have neurosurgical facilities. This article is written to help the staff of these hospitals to resolve the potential conflict between the need for rapid referral and transfer of selected patients to the neurosurgical unit and the need for thorough assessment, resuscitation, and monitoring before and during transfer.

\section{Pathophysiology of traumatic brain injury}

The biological basis of secondary traumatic brain damage is now well understood. The common denomi-

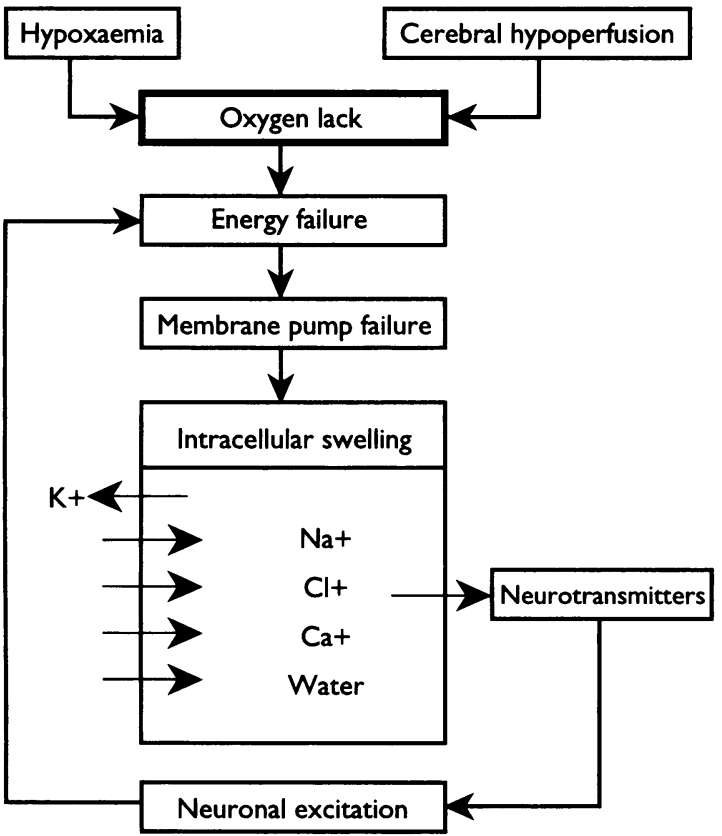

FIG 1-Metabolic events after head injury with cerebral hypoxia or ischaemia

nator linking intracranial haematomas with systemic hypoxaemia or shock is a level of cerebral tissue perfusion and oxygenation that is inadequate to meet metabolic requirements (fig 1). Mechanically injured neurones have heightened susceptibility to the effect of hypoxaemia and cerebral hypoperfusion ${ }^{5}$ and are vulnerable to damage by the high concentrations of neurotransmitters and toxic metabolites which accumulate in their extracellular environment after injury. ${ }^{67}$ Neuronal swelling, oedema, and cerebral hyperaemia from carbon dioxide retention combine to raise the intracranial pressure and lower the cerebral perfusion pressure (the difference between mean arterial blood pressure and intracranial pressure), which is the main determinant of cerebral blood flow when head injury has impaired the ability of the cerebral circulation to autoregulate in response to fluctuations in systemic blood pressure (fig 2). The situation can only be made worse if the intracranial pressure is further raised by a haematoma (fig 3) or by swelling, or if the cerebral perfusion pressure is further reduced by extracranial blood loss. The resulting positive feedback loop (fig 4) rapidly causes irreversible clinical deterioration if cerebral perfusion and oxygenation are not quickly improved. A direct line can thus be traced from adverse events at neuronal level to the early clinical management of the patient.

Many clinical studies have shown that failure to evacuate haematomas promptly or to prevent and correct hypoxaemia and hypotension carries a very high burden of mortality and morbidity. ${ }^{28-11}$. The same work has clearly shown the benefits of timely intervention. For example, mortality from extradural or subdural haematoma falls if surgery is swiftly carried out after the onset of deterioration, ${ }^{89}$ and it falls even more if surgery can pre-empt deterioration ${ }^{10}$ in patients identified as being at risk of harbouring a haematoma. ${ }^{12}$

Better airway care helps to prevent hypoxia: in one large series a rise from $11 \%$ to $82 \%$ over 11 years in the use of endotracheal intubation and ventilation during transfer to a neurosurgical unit was associated with a fall in hypoxaemia from $22 \%$ to $8 \% .^{11}$ In the same series, a reduction in the number of unidentified or undertreated major extracranial injuries from $31 \%$ to $11 \%$ was associated with a fall in hypotension from $11 \%$ to $6 \%$. Reduction in hypoxaemia and hypotension was associated with significant changes in outcome in that series: mortality fell from $45 \%$ to $32 \%$, and the proportion of patients making a good recovery or left with only moderate disability rose from $40 \%$ to $58 \%$.

\section{Initial assessment and resuscitation}

The initial assessment and resuscitation of seriously injured patients should be carried out under the supervision of experienced doctors. If not immediately available, they should be summoned promptly to the resuscitation room.

Assessment and resuscitation must proceed according to the principles of life support, following the order 

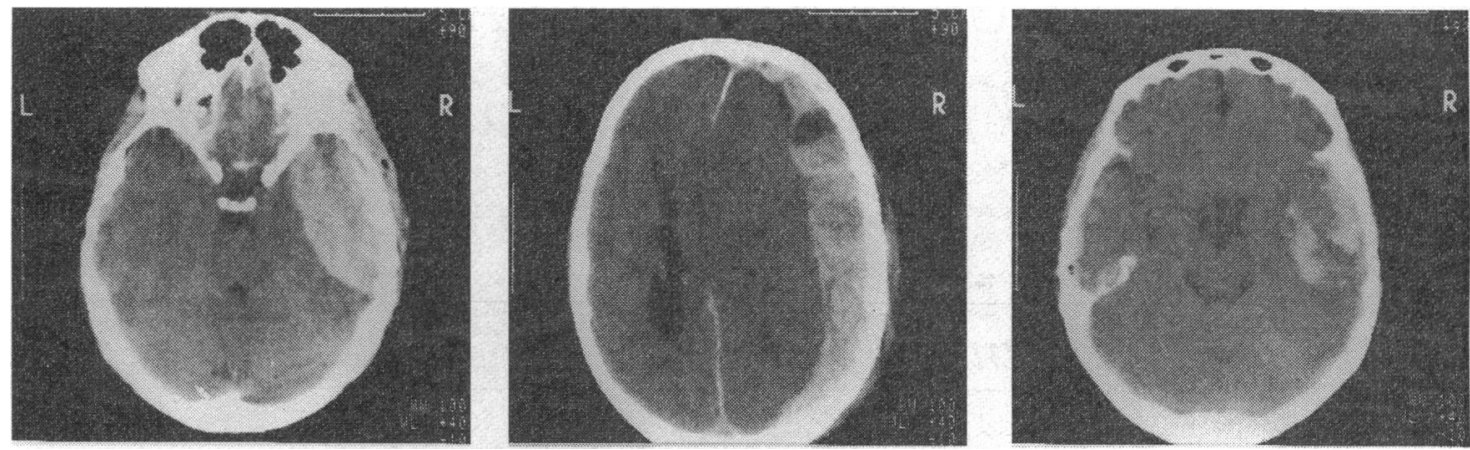

FIG 3 - Computed tomography scans showing (left) right temporal extradural haematoma; (middle) right acute subdural haematoma; (right) right temporal intracerebral haematomo

of priorities shown in box 1 and taught in the advanced trauma life support (ATLS) system. ${ }^{13}$ The identification and correction of an obstructed airway, inadequate ventilation, or shock always takes priority over a detailed assessment of the patient's neurological state.

\title{
Box 1-Priorities in resuscitation of every seriously injured patient
}

\author{
A Airway (with cervical spine control) \\ B Breathing \\ C Circulation (with haemorrhage control) \\ D Dysfunction (neurological assessment) \\ E Exposure (to identify all injuries)
}

The principles of resuscitation are the same for adults and children. However, children differ in the normal values for heart rate and blood pressure and in their tolerance to blood loss, and their smaller size imposes differences in equipment size, drug doses, fluid and electrolyte requirements, and the difficulty of carrying out procedures.

\section{A FOR AIRWAY (WITH CERVICAL SPINE CONTROL)}

The first priority must always be to secure, maintain, and protect a clear airway. Remove secretions and foreign bodies by manual extraction or suction, giving oxygen by mask (10-12 1/minute). Hold the neck immobile in line with the body, apply a rigid or semirigid cervical collar, and (unless the patient is very restless) secure the head to the trolley with sandbags and tape. Cervical spine injury can be difficult to diagnose in the unconscious patient and should be assumed to be present until it can confidently be excluded. A normal cervical spine film does not totally exclude the possibility of important cord injury. Main-

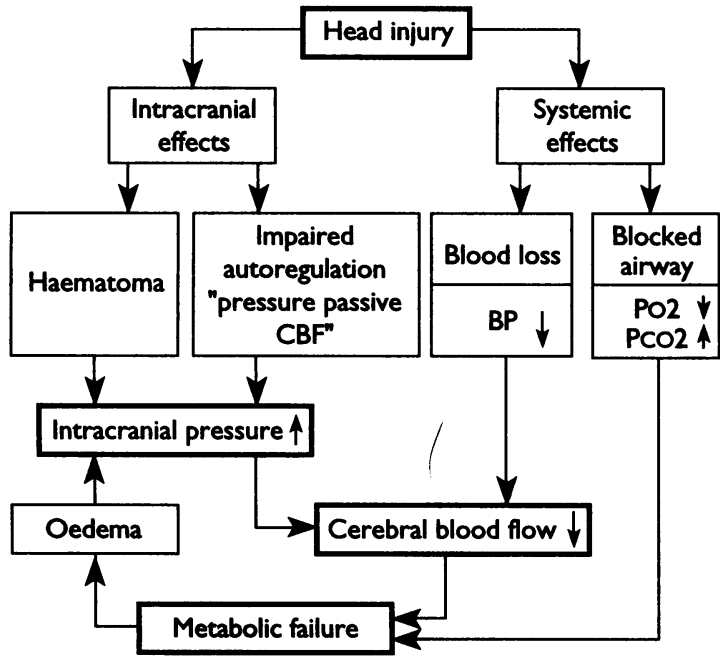

FIG 4-Interaction of intracranial and systemic adverse effects

tain aligned immobilisation of the neck when turning the patient during examination and treatment.

\section{B FOR BREATHING}

Assess the adequacy of ventilation clinically and by arterial blood gas analysis. A tension pneumothorax is a life threatening emergency which should be diagnosed clinically and treated promptly. An indwelling arterial cannula allows serial blood gas measurement and continuous recording of blood pressure. Pulse oximetry is valuable for indirect measurement of how well the patient is being oxygenated, but it can mislead if peripheral perfusion is poor, the probe is dirty or incorrectly applied, or the patient is particularly restless, and it gives no information about arterial carbon dioxide tension.

\section{Box 2-Indications for intubation and ventilation after head injury}

Immediately:

Coma (not obeying, not speaking, not eye opening), ie GCS $\leqslant 8$

Loss of protective laryngeal reflexes

Ventilatory insufficiency (as judged by blood gases): hypoxaemia $\left(\mathrm{PaO}_{2}<9 \mathrm{kPa}\right.$ on air or $<13 \mathrm{kPa}$ on oxygen)

hypercarbia $\left(\mathrm{PaCO}_{2}>6 \mathrm{kPa}\right)$

Spontaneous hyperventilation causing $\mathrm{PaCO}_{2}$ $<3.5 \mathrm{kPa}$

Respiratory arrhythmia

Before the start of the journey:

Significantly deteriorating conscious level, even if not in coma

Bilaterally fractured mandible

Copious bleeding into mouth (for example, from skull base fracture)

Seizures

An intubated patient must also be ventilated

Aim for $\mathrm{PaO}_{2}>15 \mathrm{kPa}, \mathrm{PaCO}_{2} 4 \cdot 0-4 \cdot 5 \mathrm{kPa}$.

It is sensible to consult an anaesthetist early. There are many threats to the patency of the airway or the adequacy of breathing, and some require immediate correction. Box 2 shows the indications for immediate controlled rapid sequence induction (to avoid aspiration secondary to regurgitation), orotracheal intubation (as the skull base may be fractured), and assisted ventilation. Patients with any of the features in the second part of the box, though not in immediate danger, should also be intubated and ventilated in this way if they are to be transported. Drugs should be used for sedation, analgesia, and muscle relaxation. Take great care to protect the cervical spine from movement during intubation. Use cuffed endotracheal tubes in adults (not in children under 10) and secure them with adhesive tape that does not pass round the neck (to avoid compressing venous return from the head). Check repeatedly that both sides of the chest are moving in case the tube migrates down a bronchus. 
Pass a gastric tube (ideally with a double lumen) orally to empty the stomach, which commonly dilates after trauma.

\section{FOR CIRCULATION}

Hypotension is a late sign of hypovolaemic shock, especially in children and fit young adults. Pulse rate, respiratory rate, and capillary refill time are more useful ways of assessing the circulation after injury. An isolated head injury is almost never the cause of shock.

Set up two large bore, peripheral intravenous infusions and rapidly infuse an electrolyte solution like normal saline or Hartmann's solution (not dextrose). Underinfusion is a more common error than overinfusion, and loss of more than $15 \%$ of blood volume needs correction by blood transfusion. In patients with obvious hypovolaemia, early direct monitoring of arterial pressure and central venous pressure is helpful for assessing the adequacy of resuscitation.

Identify and control sources of blood loss; have a high index of suspicion for thoracoabdominal injuries and for major pelvic and limb fractures. Delay in recognising such injuries is common ${ }^{14}$ and is associated with a high incidence of hypovolaemic shock and a poor outcome. ${ }^{11}$ A patient in persistent clinical shock despite fluid resuscitation must not be transported for computed tomography or to the neurosurgical unit until the source of continuing major blood loss has been identified and controlled as part of resuscitation -in theatre if necessary. Spinal cord transection can cause clinical shock without major blood loss, and the pulse may then be slow if the cord injury is above T1.

\section{FOR DYSFUNCTION: NEUROLOGICAL ASSESSMENT}

The patient's conscious level should be measured from the earliest possible moment by using the Glasgow Coma Scale, ${ }^{15}$ modified in the case of young children (box 3). Repeat and document the measurements often-every 10 minutes at least during the first hour in hospital. In a drunken patient who has had a head injury, never assume that altered conscious level is due simply to alcohol. Record any asymmetry of limb movements, and compare the pupils repeatedly for size and reaction to light. Any deterioration in conscious level or the development of focal neurological signs must be recorded and acted on; the patient may have become hypoxaemic or shocked, or have an expanding intracranial haematoma.

Burrhole exploration of a presumed extradural haematoma in a general hospital seldom saves life; more often the haematoma proves to be intradural or the burrholes miss it altogether, and time is wasted that would be better spent getting the patient to the neurosurgical unit. A mannitol infusion $(0 \cdot 25-1.0 \mathrm{~g} / \mathrm{kg}$ ) can buy time during transfer of a patient with clear signs clinically or on computed tomography of an expanding intracranial haematoma.

Conscious level and limb movements cannot be measured in a patient who has been pharmacologically paralysed and ventilated, but this is an acceptable price to pay for achieving cardiorespiratory stability on the way to computed tomography and definitive care. Repeated assessment of pupil size and reaction is especially important in such neurologically inaccessible patients.

\section{E FOR EXPOSURE}

Remove all clothing and check the patient for injuries from head to toe, front and back. Some injuries do not need treatment at once but will do later, and all should be documented. Call appropriate specialists to assess the patient if other injuries are found. Remember the importance of an Identiband bracelet in an unconscious patient whose clothes and personal effects have been removed.

\section{Box 3-The Glasgow coma scale and score}

In adults (score in normal adults is 15 ):

Eye opening response:

Spontaneously

To speech

To pain

None

Best motor response (in arms):

Obeys commands

Localisation to painful stimuli

Normal flexion to painful stimuli

Spastic flexion to painful stimuli

Extension to painful stimuli

None

Best verbal response:

Oriented

Confused

Inappropriate words

Incomprehensible sounds

None

Modifications of normal responses in children under 5

\begin{tabular}{|c|c|c|}
\hline & $\begin{array}{l}\text { Best motor } \\
\text { response }\end{array}$ & $\begin{array}{l}\text { Best verbal } \\
\text { response }\end{array}$ \\
\hline $\begin{array}{l}6 \text { months } \\
12 \text { months }\end{array}$ & $\begin{array}{l}\text { Flexion } \\
\text { Localisation }\end{array}$ & $\begin{array}{l}\text { Smiles and cries } \\
\text { Smiles and cries }\end{array}$ \\
\hline years & $\begin{array}{l}\text { Localisation } \\
\text { Obeys commands }\end{array}$ & $\begin{array}{l}\text { Sounds and words } \\
\text { Words and phrases }\end{array}$ \\
\hline
\end{tabular}

\section{MONITORING THE PATIENT}

After assessing the patient's airway, breathing, and circulation, begin monitoring. Continue monitoring when the patient is transferred. The minimum standards of monitoring for anaesthesia recommended by the Association of Anaesthetists apply equally to a seriously injured patient during resuscitation and transfer: continuous monitoring of blood pressure, electrocardiography, oxygen saturation, and urine output (by catheter). ${ }^{16}$ In ventilated patients monitor end tidal carbon dioxide concentrations and check arterial blood gas concentrations repeatedly, keeping arterial oxygen tension above $13 \mathrm{kPa}$ and arterial carbon dioxide tension around $4 \mathrm{kPa}$. Avoid excessive hyperventilation, which can depress the myocardium and induce cerebral ischaemia.

\section{DRUG TREATMENT}

Drugs used to assist ventilation have been mentioned above. With this exception, avoid drugs which depress conscious level. Giving other drugs may be appropriate after discussion with the neurosurgeon. For example, repeated seizures may be controlled with phenytoin (5-10 mg/kg) by slow intravenous injection, with continuous electrocardiographic monitoring.

\section{Referral to the neurosurgeon}

WHICH PATIENTS SHOULD BE REFERRED?

Criteria for referring head injured adults and children to the neurosurgeon have been published previously ${ }^{12} 17$ and are widely accepted in the United Kingdom. These are summarised in box 4. Transfer the patient only after the neurosurgeon has agreed to receive the patient and has approved the arrangements for transfer (see below).

WHAT DOES THE NEUROSURGEON NEED TO KNOW?

Box 5 shows the information the neurosurgeon needs to decide on the necessity for transfer and its timing. This information will have been obtained during initial assessment and resuscitation, and it should be available at the time of referral. There is limited value in discussing a patient who has not yet been fully assessed and resuscitated, and resuscitation takes priority. 


\section{Box 4-Criteria for referring head injured patients to a neurosurgical unit}

Immediately after initial assessment and resuscitation: Fractured skull, with:

Any alteration of conscious level (Glasgow coma score $<15$ ) or

Focal neurological signs or

Fits or

Any other neurological symptoms or signs

Coma persisting after resuscitation ] even without

Deterioration of conscious level a skull

Focal pupil or limb signs $\quad$ fracture

Urgently, not necessarily immediately:

Confusion persisting $>6$ hours (even without a skull fracture)

Compound depressed skull fracture (or other penetrating injury)

Suspected leak of cerebrospinal fluid from nose or ear

Persistent or worsening headache or vomiting (especially in a child)

Nowadays the indications for urgent computed tomography scanning include coma and any alteration of conscious level associated with a skull fracture (fig 5) or with multiple injuries. The finding of a skull fracture on $x$ ray films plays a relatively greater part in decision making about the need for scanning and specialist referral in the United Kingdom than in the United States, where scanners are more widely available. If a decision is taken on other grounds that computed tomography is indicated, skull radiographs assume less importance.

Increasingly a computed tomography scan is available at the time of referral to the neurosurgeon; however, obtaining a scan must not take priority over complete resuscitation or prolong unduly the assessment time before referral. Image transfer systems are now available in some centres and allow the neurosurgeon to see a scan done in another hospital. This can help to guide decisions about priorities in management and the timing of transfer to the neurosurgical unit.

\section{Transferring the patient}

The journey from the resuscitation room to the neurosurgical unit is fraught with danger for the patient. ${ }^{18}$ The distance travelled is not the main factor;

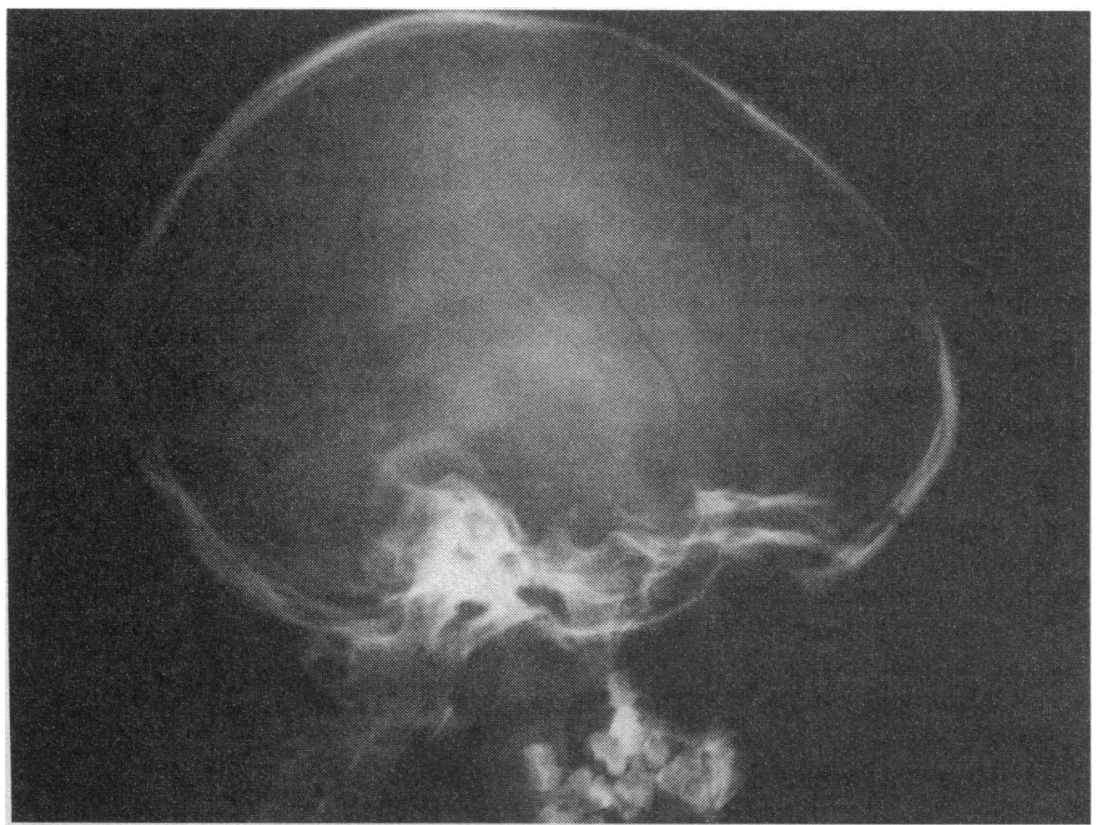

FG 5-Lateral skull film showing multiple right frontal linear fractures hypoxaemia and hypercarbia can develop insidiously within a few minutes because of an obstructed airway or inadequate ventilation, and even transfer within a hospital needs to be taken seriously. ${ }^{19}$ The physical disturbance caused by an ambulance journey and by movement into and out of the ambulance can adversely affect cardiovascular stability in a seriously injured patient. Undesirable changes in the patient's homoeostasis may go unnoticed or untreated because of inadequate monitoring, lack of equipment and drugs, or inexperienced escorts. The good work done in the resuscitation room is then undone during the journey, and the patient is no longer stable when presented to the neurosurgical team. Serious failures of communication can compound the problem if the escorts are poorly briefed or leave before handing over properly.

Many of these problems stem from the inexperience of the staff involved. Medical and nurse staffing levels prevent the formation of dedicated trauma transfer teams to travel from major centres to collect severely injured patients, although the value of such teams has been clearly shown for critically ill patients. ${ }^{2021} \mathrm{~A}$ more practical solution is to give doctors in appropriate

Box 5-What the neurosurgeon needs to know at the time of referral

Patient's age and previous medical history (if known)

History of injury:

Time of injury

Cause and mechanism (for example, height of fall)

Neurological state:

Talked or not after injury

Conscious level on arrival at hospital

Trend in conscious level since admission

Pupil and limb responses

Cardiorespiratory state:

Blood pressure and pulse rate

Arterial blood gases

Respiratory rate and pattern

Injuries:

Skull fracture

Extracranial injuries

Management so far:

Airway protection and ventilatory status

Circulatory status and fluid therapy

First aid treatment of associated injuries

Proposed emergency investigations or surgery

Monitoring

Drug doses and times of administration

specialties systematic training in the skills needed to transfer patients safely-another reason to involve experienced clinicians early on in the resuscitation and transport of seriously injured patients. Locally agreed transfer protocols are useful, and to be effective they must not only be based on sound principles but also reflect local circumstances.

\section{TIMING OF TRANSFER}

The decision that a patient has been rendered stable for transfer requires experience and follows a period of monitoring in the resuscitation room, which continues during the journey. This can legitimately delay the actual transfer, and it is helpful to telephone the neurosurgical unit as the journey starts to give the estimated time of arrival. Never start a journey with an unstable patient because of the high risk of complications during the journey.

\section{THE ESCORT}

As a bare minimum the severely head injured patient must be escorted by a doctor and a trained nurse or paramedic. They are professionally responsible for the patient until they hand over after reaching the neurosurgical unit. They must be well informed about the 
patient before the journey starts, and ideally should have been involved in the resuscitation room. They must know about what can go wrong during the journey and must have the skills and equipment needed to identify and deal with these problems. In particular, they must be able to guarantee the safety of the airway.

It follows that both doctor and nurse should have experience in assessing and managing seriously injured patients. Anaesthetic skills are particularly valuable for airway care and for sophisticated monitoring during the journey. An anaesthetist (or at least a doctor with anaesthetic training and experience) must escort every intubated and ventilated patient. A pre-registration house officer is not an appropriate escort for a seriously head injured patient, nor is a nurse hastily recruited from another department who knows nothing about the patient nor what to do during the journey.

\section{MONITORING}

It is unwise to rely solely on eyes and ears when monitoring a patient in the back of a noisy, dark, and moving ambulance. During transfer continue the monitoring started in the resuscitation room, as described above. There must be reliable intravenous access. The electrocardiogram should be monitored continuously, as should the blood pressure (as sphygmomanometry is unreliable in a noisy moving ambulance). The use of disposable transducers compatible with the equipment at the neurosurgical unit simplifies handover and the release of equipment for return to the referring hospital. All lines must be secured, and arterial and central venous lines should be clearly labelled to prevent inadvertent drug injection through them. An injured patient quickly becomes cold in an ambulance and should be wrapped in blankets or preferably a space blanket.

Pulse oximeters are easy to use and give an indirect measure of oxygen delivery to the tissues, but the information they give must be interpreted cautiously in a poorly perfused patient. Movement artefacts occasionally make the recordings useless. In a ventilated patient, a capnograph to measure end tidal carbon dioxide is useful to monitor the adequacy of ventilation, although the currently available equipment is rather cumbersome. The ventilator itself should have a pressure dial to indicate inflation pressure and a blow off valve to avoid barotrauma. There should be a system to deliver high flow oxygen to the patient, and two oxygen cylinders should be carried, both full and both checked before use.

It is not enough to attach the equipment to the patient; the information it gives must be carefully monitored, and this is a prime function of the escorts during the journey. The array of monitoring equipment carried in ambulances grows ever larger and more sophisticated ${ }^{22}$; when choosing what to buy it is worth remembering that some modern monitors have the ability to monitor trends and to print out a hard copyuseful for later audit of the transfer.

An unfamiliar monitor or a piece of equipment that fails to work when needed is useless or even dangerous. All monitoring and other equipment used for patient transfer should be regularly serviced, disposables replaced, and drugs regualrly checked for expiry date and replaced when used.

\section{OTHER EQUIPMENT AND DRUGS}

Anticipate emergencies which may occur en route, and carry the equipment and drugs to deal with thempreferably as a special box or bag that does not have to be put together every time a patient is transferred. The doctor and nurse escorts must be familiar with the equipment they carry, which should be standard and
Box 6-Recommended sizes of endotracheal tubes

\begin{tabular}{|c|c|c|c|}
\hline & \multicolumn{2}{|c|}{ Length $(\mathrm{cm})$} & \multirow[b]{2}{*}{ Size } \\
\hline & Oral & Nasal & \\
\hline \multicolumn{4}{|l|}{ Adults } \\
\hline Men & $24 \cdot 0$ & $27 \cdot 0$ & $9 \mathrm{~mm}$ cuffed \\
\hline Women & $22 \cdot 0$ & $25 \cdot 0$ & $8 \mathrm{~mm}$ cuffed \\
\hline \multicolumn{4}{|l|}{ Children: } \\
\hline 3 months & $11 \cdot 0$ & $13 \cdot 0$ & $3.5 \mathrm{~mm}$ \\
\hline 6 months & 11.5 & $14 \cdot 0$ & $4 \mathrm{~mm}$ \\
\hline 1 year & $12 \cdot 0$ & $14 \cdot 5$ & $4 \mathrm{~mm}$ \\
\hline 2 years & $13 \cdot 0$ & $15 \cdot 5$ & $4.5 \mathrm{~mm}$ \\
\hline 5 years & 13.5 & $16 \cdot 5$ & $5 \mathrm{~mm}$ \\
\hline 7 years & $15 \cdot 5$ & $18 \cdot 0$ & $6 \mathrm{~mm}$ \\
\hline 10 years & $18 \cdot 0$ & $19 \cdot 5$ & $6 \mathrm{~mm}$ cuffed \\
\hline 14 years & $20 \cdot 0$ & $22 \cdot 0$ & $7 \mathrm{~mm}$ cuffed \\
\hline \multicolumn{4}{|c|}{$\begin{array}{l}\text { Use uncuffed tubes in children aged under } 10 \text { years. } \\
\text { Oral tube length should be approximately } 1.5 \text { times } \\
\text { the distance from angle of jaw to tip of chin. } \\
\text { Nasal tube length should be approximately twice the } \\
\text { distance from angle of jaw to tip of chin. }\end{array}$} \\
\hline
\end{tabular}

preferably compatible with the equipment at the neurosurgical unit.

Even if the patient has been intubated before transfer it may be necessary to reposition or replace a tube which obstructs or falls out, and the ambulance must carry a range of endotracheal tubes and two working laryngoscopes. Box 6 shows suitable sizes of endotracheal tubes for men, women, and children. The oxygen supply can fail, and it is always advisable to carry a self inflating bag (for example, an Ambu bag) to let ventilation of the patient continue. Intravenous lines inserted before transfer may block or fall out or may have to be supplemented for rapid fluid infusion during transfer. A range of cannulas (including wide bore) should be carried, as well as crystalloid (for example, Hartmann's solution) for infusion. If blood has been cross matched before the journey it should travel in the ambulance, not in a separate taxi.

The escorts should carry drugs for cardiac resuscitation: non-depolarising muscle relaxants and short acting analgesics and sedatives for controlling ventilation; anticonvulsants; and mannitol.

\section{THE AMBULANCE AND TROLLEY}

Modern ambulances offer a smooth, quiet ride with reasonable space and lighting, but the problems of working in any moving vehicle make it vital to stabilise the patient and set up monitoring before transfer. The ambulance rarely needs to travel at great speed, which can worsen cardiovascular instability; a smooth ride at constant speed is safer. The patient should be placed head first in the ambulance, so as better to tolerate any sudden deceleration during the journey. A head up tilt of $10-15^{\circ}$ should be maintained throughout the ambulance journey and when moving the patient through the hospital (including manoeuvres up and down ramps). If life saving procedures like endotracheal intubation have to be carried out along the way it is more sensible to stop the ambulance briefly than to attempt heroics under poor conditions, exposing the patient to the risks of failure or delay in carrying out the procedure.

Occasionally an ambulance crashes. The referring hospital must carry adequate insurance for injuries sustained on the way to or from the neurosurgical unit by the escorts, for whom the ambulance is simply an extension of their hospital.

The patient should be moved between trolleys the minimum number of times. Ideally a single trolley should be used from the resuscitation room into the 
ambulance and out again at the neurosurgical unit, where the patient can be transferred to the computed tomography table and then on to a bed or operating table. A fully equipped dedicated transfer trolley should be kept in every major accident department, with its equipment running off the ambulance power during transfer.

A very small proportion of seriously head injured patients travel to the neurosurgical unit by air for reasons of distance, terrain, or traffic. Noise and lack of space are even more obvious, and oxygen tension can be considerably lowered during flight unless supplemental oxygen is given.

\section{THE HANDOVER}

The escorts must be able to give the neurosurgical staff an accurate description of all injuries, the trends in conscious level and neurological signs since injury or admission, and the drugs and intravenous fluids given. They should not leave until this has been done. The neurosurgical team may need further information later and must know who to contact. All medical and nursing clinical notes, observation charts, drug prescription sheets, and $x$ ray films and scans should be left with the neurosurgical team. There are obvious advantages to having observation charts and case records standardised throughout a region.

\section{THE AFTERMATH OF TRANSFER: IDENTIFYING AND} SOLVING PROBLEMS

Identifying and overcoming problems in resuscitation and transfer is difficult, but must be done if standards are to rise. Recent studies from the south of England have confirmed that many hospitals cannot supply invasive blood pressure monitoring (77\%), pulse oximetry $(54 \%)$, or even a portable ventilator $(30 \%)$ for transfer; and that many head injured patients arrive at the neurosurgical unit in hypovolaemic shock from missed and untreated extracranial injuries or from gagging on an endotracheal tube because of poor use of relaxant or sedative drugs. ${ }^{23-25} \mathrm{We}$ can and must do better than this.

Neurosurgeons have a special responsibility for helping to educate and train the junior medical and nursing staff in their referring hospitals, who usually bear the brunt of initial trauma care and who change often. It is good practice for the neurosurgical team to complete a short form after every transfer and return it quickly to the doctors and nurses who treated and escorted the patient, highlighting any concerns thought to stem from the transfer itself or from management at the referring hospital. By the same token, the referring team and escorts should tell the neurosurgical unit about problems they perceive with individual transfers and handovers. Experienced clinicians from both hospitals should audit each case where a problem is raised by either side, to agree ways of avoiding these in future. In this way the locally agreed protocols for referral and transfer can be constantly refined.

Feedback must be even handed; a safe transfer should attract thanks from the neurosurgical team, as an important contribution to the care of the patient. Indeed, it is particularly important that all comments should be constructive and educational; negative remarks or vague criticisms of the work of others simply engender hostility and make it more difficult to agree that a problem has occurred and how it can be prevented in the future. Every effort must be made to reinforce the message that the referring and recipient doctors and nurses are not in competition with each other but form one team whose sole purpose is to help the patient.

1 Rose J, Valtonen S, Jennett B. Avoidable factors contributing to death after injury. $B M \mathcal{F} 1977$;ii:615-8.

2 Miller JD, Becker DP. Secondary insults to the injured brain. $f R$ Coll Surg Edinb 1982;27:292-8.

3 Gentleman D. Preventing secondary brain damage after head injury: multidisciplinary challenge. Injury 1990;21:305-8.

4 Goldstein M. Traumatic brain injury: a silent epidemic. Ann Neurol 1990;27: 327.

5 Ishige N, Pitts LH, Hashimoto T, Nishimura MC, Bartkowski HM. Effect of hypoxia on traumatic brain injury in rats. Neurosurgery 1987;20:848-58

6 Faden AI, Demediuk P, Panter SS, Vink R. The role of excitatory amino-acids and NMDA receptors in traumatic brain injury. Science 1989;244:798-800.

7 Desalles AAF, Kontos HA, Becker DP, Yang MS, Ward JD, Moulton R, et al. Prognostic significance of ventricular CSF lactic acidosis in severe head. injury. I Neurosurg 1986;65:615-24.

8 Mendelow AD, Karmi MZ, Paul KS, Fuller GAG, Gillingham FJ. Extradural haematoma: effect of delayed treatment. BMF 1979;i:1240-2.

9 Seelig JM, Becker DP, Miller JD, Greenberg RP, Ward JD, Choi SC Traumatic acute subdural haematoma: major mortality reduction in comatose patients treated within four hours. N Engl f Med 1981;304:1511-8.

10 Teasdale G, Galbraith S, Murray L, Ward P, Gentleman D, McKean M Management of traumatic intracranial haematoma. $B M \mp 1$ 1982;285:1695-7.

11 Gentleman D. Causes and effects of systemic complications among severely head injured patients transferred to a neurosurgical unit. Int Surg 1992;77: 297-302.

12 Teasdale GM, Murray G, Anderson E, Mendelow AD, MacMillar R, Jennett $B$, et al. Risks of acute traumatic intracranial haematoma in children and adults: implications for managing head injuries. BMF 1990;300:363-7.

13 American College of Surgeons Committee on Trauma. ATLS course manual. Chicago: American College of Surgeons, 1993.

14 McLaren CAN, Robertson C, Little K. Missed orthopaedic injuries in the resuscitation room. I $R$ Coll Surg Edinb 1983;28:399-401.

15 Teasdale G, Jennett B. Assessment of coma and impaired consciousness. Lancet 1974; ii: $81-4$

16 Association of anaesthetists of Great Britain and Ireland. Recommendations for standards of monitoring during anaesthesia and recovery. London: Association of Anaesthetists, 1988.

17 Guidelines for initial management after head injury in adults. Suggestions from a group of neurosurgeons. $B M \mathcal{f} 1984 ; 288: 983-5$.

18 Gentleman D, Jennett B. Audit of unconscious head injured patients transferred to a neurosurgical unit. Lancet 1990;i:327-30.

19 Andrews PJD, Piper IR, Dearden NR, Miller JD. Secondary insults during intrahospital transfer of head injured patients. Lancet 1990;335:327-30.

20 Reeve W, Runcie CJ, Reidy J, Wallace PGM. Current practice in transferring critically ill patients among hospitals in the West of Scotland. BMY 1990;300:85-7.

21 Bion JF, Wilson IH, Taylor PA. Transporting critically ill patients by ambulance: audit by sickness scoring. $B M^{f}$ 1988;296:170.

22 Runcie CJ, Reeve WR, Wallace PGM. Preparation of the critically ill for interhospital transfer. Anaesthesia 1992;47:327-31.

23 Vyvyan HAL, Kee S, Bristow A. A survey of secondary transfers of head injured patients in the south of England. Anaesthesia 1991;46:395-7.

24 Lambert SM, Willett $K$. Transfer of multiply injured patients for neurosurgica opinion: a study of the adequacy of assessment and resuscitation. Injur 1993;24:333-6.

25 Munro HM, Laycock JRD. Inter-hospital transfer: standards for ventilated neurosurgical emergencies. Br f Intensive Care 1993;3:210-4.

(Accepted 13 fuly 1993)

\section{Correction}

ABC of one to seven: Audit in primary care paediatrics

Two author's errors occurred in this article by L Peter ( 3 July, pp 51-3), both in the section headed "Sample size for audit (rule of thumb)." Firstly, Oxfordshire Medical Audit Advisory Group should have been credited as the source of this section of the article and the accompanying graph. Secondly, the last two numbers on the $x$ axis of the graph should be 3000 and 5000, not 1200 and 1400 . 